\section{Assessment of direct versus indirect magnetic bead-based T-cell isolation procedures followed by magnetic bead-based DNA isolation}

To cite: Rosenbaum A, Bleck E, Schneider M, et al. Assessment of direct versus indirect magnetic bead-based T-cell isolation procedures followed by magnetic bead-based DNA isolation. Lupus Science \& Medicine 2016:3:e000167. doi:10.1136/lupus-2016 000167

Received 23 May 2016 Accepted 25 June 2016

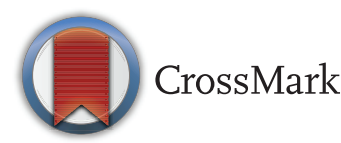

Medical Faculty, Hiller Research Center Rheumatology at University Hospital Düsseldorf, Heinrich-Heine-University, Düsseldorf, Germany

Correspondence to Dr Stefan Vordenbäumen; Stefan.Vordenbaeumen@ med.uni-duesseldorf.de

\section{ABSTRACT}

Objective: To compare direct and indirect bead-based T-cell isolation followed by magnetic bead-based DNA isolation.

Methods: T-cells were isolated by direct or indirect selection with magnetic bead coated antbiodies followed by magnetic bead-based automated DNA isolation in 10 healthy subjects. Purity of T-cells, purity of DNA (by A260/A280 ratio measurement) and DNA concentration were assessed.

Results: Direct and indirect labelling resulted in comparable T-cell purity $(93.11 \pm 1.47 \%$ vs. $94.99 \pm 1.54 \%, p=0.125)$ and DNA concentration per cell $(50.97 \pm 14.15 \mathrm{ng} /$ (mlxcell) vs. $49.53 \pm 13.62$ $\mathrm{ng} /(\mathrm{mlxcell}), \mathrm{p}=0.492$ ), while DNA purity was significantly higher after direct labelling $(1.82 \pm 0.05$ vs. $1.78 \pm 0.03, p=0.0488$ ).

Conclusions: Both direct and indirect magnetic beadbased T-cell selection may be used prior to magnetic bead-based DNA isolation procedures.

Sir, we read with interest the article of Renauer $e t a l^{1}$ who recently analysed epigenetic modifications in $\mathrm{T}$ cells of patients with systemic lupus erythematosus (SLE) and related them to phenotypic manifestations of the disease. Our group is similarly interested in epigenetics of SLE and the construction of biorepositories. ${ }^{2}$ We noted that Renauer et al selected CD4+ T cells by magnetic bead-based negative selection and subsequently extracted DNA manually. Indeed, isolation and analysis of DNA from distinct cellular subsets is an increasingly used tool in immunological research. For example, epigenetic DNA modifications such as methylation are often critically responsible for diversity and plasticity of immune cells within the complex human immune network, ${ }^{3}{ }^{4}$ and as shown by Renauer et $a l^{1}{ }^{1}$ this may translate into phenotypic manifestations of SLE. Magnetic microbeads are a cost-efficient means of isolating distinct cellular subsets by either direct labelling of target cells or indirect selection following labelling and eradication of non-target immune cells, as employed by Renauer et al. ${ }^{15}$ Besides manual extraction of DNA, magnetic bead-based procedures are among the choices for subsequent DNA or RNA isolation with the advantages of potential automatisation and good quality. ${ }^{2}{ }^{6}$ However, interactions with the previous magnetic bead-based cellular isolation procedure have not been systematically assessed previously and are a source of concern.

We therefore compared two commercially available magnetic bead-based CD4+ T-cell isolation kits and subsequent magnetic beadbased automatic isolation of DNA from CD4+ cells by the MagCore instrument (MagCore Genomic DNA Whole Blood Kit, RBC Bioscience, New Taipei City, Taiwan) on 10 healthy subjects (5 males, 5 females 28.5 \pm 4.1 years). The following CD4+ T-cell isolation kits were assessed: CD4 MicroBeads human employs direct labelling (direct), and CD4+ T-cell isolation kit human employs indirect labelling of non-CD4+ cells (indirect). Blood was collected in three $5 \mathrm{~mL}$ EDTA tubes $(3 \mathrm{~mL}$ each) and promptly processed. Peripheral mononuclear cells were isolated from $4 \mathrm{~mL}$ EDTA blood by density gradient centrifugation with Leucosep (Greiner Bio-One GmbH, Frickenhausen, Germany) and Lymphoprep (AXIS-SHIELD PoC AS, Oslo, Norway) followed by magnetic bead-based separation (Miltenyi Biotec $\mathrm{GmbH}$ ) according to manufacturer's instructions. After separations, the cells were counted and their purity assessed with CD3 labelling on MACSQuant Analyzer 10 for five subjects. Data analysis was performed by MACSQuantify software (all Miltenyi Biotec $\mathrm{GmbH})$. DNA was automatically isolated 
Table 1 Quantitative and qualitative comparison of direct and indirect magnetic bead-based CD4+ T-cell isolation kits with subsequent bead-based DNA isolation

\begin{tabular}{llcll}
\hline Parameter & $\begin{array}{l}\text { CD4 MicroBeads kit } \\
\text { (direct) }\end{array}$ & $\begin{array}{l}\text { CD4+T cell isolation kit } \\
\text { (indirect) }\end{array}$ & p Value & $\begin{array}{l}\text { Hedges' g } \\
\text { (95\% Cl) }\end{array}$ \\
\hline A260/A280 & $1.82 \pm 0.05$ & $1.78 \pm 0.03$ & $\mathbf{0 . 0 4 8 8}$ & $0.88(-0.03$ to 1.80$)$ \\
C(DNA) $(\mu \mathrm{g} / \mathrm{mL})$ & $59.55 \pm 27.42$ & $53.00 \pm 19.95$ & 0.0924 & $0.26(-0.62$ to 1.14$)$ \\
c(DNA) $(\mathrm{ng} /(\mathrm{mlxcell}))$ & $50.97 \pm 14.15$ & $49.53 \pm 13.62$ & 0.4922 & $0.10(-0.78$ to 0,98$)$ \\
Purity CD3+ $(\%)$ & $93.11 \pm 1.47$ & $94.99 \pm 1.54$ & 0.1250 & $-1.1(-2.46$ to 0.21$)$ \\
\hline
\end{tabular}

p-value according to Wilcoxon matched-pairs signed-rank test (significant results with $p<0.05$ printed in bold), effect size estimated by Hedges' G with $95 \% \mathrm{Cl}$.

using MagCore. Afterwards, DNA purity was estimated by 260/280 ratio and quantified on Nano Photometer P330 (Implen GmbH, München, Germany). Parameters of quality and quantity were compared by Wilcoxon matched-pairs signed-rank test with $\mathrm{p}<0.05$ considered significant. Effect sizes were estimated by Hedges' $\mathrm{g}$.

As can be seen in table 1, DNA purity estimated by A260/A280 ratio was significantly higher, with a strong effect size after direct labelling. Total DNA concentration showed a trend towards higher values after direct isolation as well. This was due to a higher yield in the number of isolated cells, as reflected by a lack of difference after correction for cell number. Finally, purity of isolated $\mathrm{T}$ cell was high for both direct and indirect labelling. Hence, direct labelling of $\mathrm{CD} 4+$ cells by magnetic beads does not seem to interfere with subsequent magnetic bead-based DNA labelling, as demonstrated by a comparable performance. Moreover, both kits offer a high purity of target cells.

Our experiments show that both direct and indirect magnetic bead-based cellular selection may be used with subsequent bead-based DNA isolation. Direct labelling carries the advantage that flushed cells are free of antibody labelling and can be subjected to further selection processes, for instance to additionally gain B cells. Conversely, indirect labelling would be a better choice, if potential activation of immune cells by the labelling procedures would preclude subsequent experiments.

In conclusion, our experiments show that valuable epigenetic analyses such as those reported by Renauer et al may be carried out with greater flexibility (eg, direct or indirect labelling) and the potential for automatisation by sequentially using magnetic beads. This in turn may increase validity and allow for higher sample numbers to be analysed in future epigenetic studies.
Acknowledgements The authors gratefully acknowledge financial support of this study from the Hiller Foundation, Erkrath, Germany.

Contributors AR: data acquisition, data analysis, manuscript draft. EB: data acquisition. MS: conceived the study. GP: data acquisition. SV: conceived study, data acquisition, data analysis, manuscript draft. All authors: data interpretation, final approval.

Competing interests None declared.

Ethics approval Ethics committee of the Medical Faculty, Heinrich-Heine-University, Düsseldorf, Germany.

Provenance and peer review Not commissioned; internally peer reviewed.

Open Access This is an Open Access article distributed in accordance with the Creative Commons Attribution Non Commercial (CC BY-NC 4.0) license, which permits others to distribute, remix, adapt, build upon this work noncommercially, and license their derivative works on different terms, provided the original work is properly cited and the use is non-commercial. See: http:// creativecommons.org/licenses/by-nc/4.0/

\section{REFERENCES}

1. Renauer $P$, Coit $P$, Jeffries $M A$, et al. DNA methylation patterns in naïve CD4+ T cells identify epigenetic susceptibility loci for malar rash and discoid rash in systemic lupus erythematosus. Lupus Sci Med 2015;2:e000101.

2. Vordenbäumen S, Bleck E, Brinks R, et al. Assessment of magnetic bead-based automated whole blood RNA-isolation from a validated RNA stabilization reagent (Tempus Blood RNA). J Immunol Methods 2014;406:148-9.

3. Satoh T, Tajima M, Wakita D, et al. The development of IL-17/ IFN- $\gamma$-double producing CTLs from Tc17 cells is driven by epigenetic suppression of Socs3 gene promoter. Eur J Immunol 2012;42:2329-42.

4. Schmidl C, Hansmann L, Andreesen R, et al. Epigenetic reprogramming of the RORC locus during in vitro expansion is a distinctive feature of human memory but not naïve Treg. Eur $J$ Immunol 2011:41:1491-8.

5. Grützkau A, Radbruch A. Small but mighty: how the MACS-technology based on nanosized superparamagnetic particles has helped to analyze the immune system within the last 20 years. Cytom Part J Int Soc Anal Cytol 2010;77:643-7.

6. Mathot L, Wallin M, Sjöblom T. Automated serial extraction of DNA and RNA from biobanked tissue specimens. BMC Biotechnol 2013;13:66. 